\title{
A DEMOCRACIA INACABADA: RELAÇÕES SOCIEDADE-ESTADO NO CONTEXTO DA POLÍTICA PONTO DE CULTURA EM ALAGOAS
}

\author{
Anne Gillman ${ }^{1}$
}

\begin{abstract}
Resumo
Este artigo apresenta os resultados preliminares de um estudo qualitativo de Pontos de Cultura no Estado de Alagoas, refletindo sobre como o programa pode alterar as relações Estado-sociedade, de maneiras que impulsionam processos de democratização. Em primeiro lugar, o programa facilita relações entre gestores estaduais e participantes, acarretando aprendizagens que ajudam os pontistas a exercer seus direitos como cidadãos. Em segundo lugar, para além dos serviços públicos diretamente entregues por Pontos, ele permite parcerias que contribuem com a capacidade do governo local para fornecer bens públicos. Finalmente, ele aumenta a autonomia dos participantes frente aos poderes locais, ajudando-os a realizar atividades culturais independentes da dinâmica política. Os exemplos apresentados não representam a totalidade do programa, mas sugerem o seu potencial.
\end{abstract}

Palavras-chave: Alagoas. Democratização. Cultura Viva. Ponto de Cultura.

\begin{abstract}
This article presents preliminary findings from a qualitative study of the Pontos de Cultura program in the state of Alagoas, reflecting on how the program may alter statesociety relations in ways that advance ongoing processes of democratization. Firstly, the program facilitates relationships between state cultural managers and Pontos participants, or "pontistas", leading to learning that helps pontistas access public resources and assert their rights as citizens. Secondly, beyond the public services directly delivered by Pontos, it enables partnerships that may build local government capacity to provide public goods. Finally, it insulates pontistas from abuses of local power, helping them realize cultural activities independent of political dynamics. Examples presented are not intended to represent the entirety of the program, but rather suggest its potential.
\end{abstract}

Keywords: Alagoas. Democratization. Cultura Viva. Pontos de Cultura.

\section{Introdução}

\footnotetext{
${ }^{1}$ Doutoranda em ciência política pela John Hopkins University em Baltimore, MD. A pesquisa foi realizada com o apoio da Fundação Interamericana e do Social Science Research Council. Também agradeço à Casa Rui Barbosa, pelo apoio institucional. e-mail: gillman.anne@gmail.com.
} 
Célio Turino, hoje conhecido como fundador da política cultural Cultura Viva, gosta de citar Paulo Freire: "Onde há vida, há inacabamento" (FREIRE, 1997, p. 55). Poderíamos também dizer que onde há democracia, há inacabamento. Se nas ciências políticas de anos atrás se entendeu a democratização como um evento pontual, hoje em dia existe um volume de literatura que a reconhece como um processo contínuo e desequilibrado, pelo território nacional, com avanços e retrocessos, até a democracia chegar "na ponta", num país tão grande e diversificado como o Brasil. Como uma política que intenta chegar justamente "na ponta" e transformar a relação entre o Estado brasileiro e seu povo, o Ponto de Cultura tem um papel importante no processo contínuo da democratização. Na prática, como funciona este processo? Especificamente, qual é o impacto do programa Cultura Viva na relação entre Estado e cidadão?

Este artigo aborda estas perguntas através dum estudo de caso da política cultural Ponto de Cultura, no Estado de Alagoas. Oferece exemplos de três tipos de mudanças nas relações Estado-sociedade, acontecendo no contexto do programa: 1) uma aproximação entre gestores públicos e "pontistas" (como alagoanos que participam em Pontos de Cultura se autorreferem), que os ajuda a adquirir capacidades necessárias para exercer seus direitos como cidadãos; 2) o estabelecimento de parcerias entre Pontos e governos municipais, que aumenta a capacidade estadual do poder público local, e; 3) o aumento de autonomia política, frente aos poderes locais, de agentes culturais reconhecidos como Pontos. As conclusões são baseadas numa metodologia qualitativa, que incluiu vinte e cinco entrevistas semiestruturadas, com diversos "pontistas", como alagoanos que participam em Pontos de Cultura se autorreferem, e com gestores públicos, nos níveis municipal e estadual. Incluiu, ainda, a observação participante nas atividades culturais de três Pontos de Cultura, dois urbanos e um rural, e de reuniões entre pontistas e representantes estaduais.

Merece destacar que este trabalho de pesquisa também é um projeto inacabado, e as observações aqui compartilhadas são preliminares. Dada a diversidade de perfis e experiências de Pontos de Cultura, em Alagoas, a mostra aqui não serve para representar o todo. Em certa medida, "cada caso é um caso", quando se trata de Pontos de Cultura. Este artigo talvez sirva mais para provocar perguntas do que resolvê-las. 
Políticas Culturais em Revista, 2(7), p. 178-191, 2014 - www.politicasculturaisemrevista.ufba.br

\section{Processos de democratização}

$\mathrm{Na}$ literatura dominante das ciências políticas, costumava-se conceituar a democratização como um momento ou um período no qual um país se converte numa democracia, seja através de revolução, seja através de uma transição negociada. Críticos desta perspectiva anotaram que, apesar de suas instituições formais, muitas democracias eram pouco democráticas; os recursos públicos e a voz política ainda se concentravam entre uma minoria dominante. Reconhecia-se a ausência do Estado em certos espaços do território nacional, espaços que Guillermo O’Donnell chama de "brown zones," (zonas marrons) (O’DONNELL, 1986). Mesmo nas supostamente velhas democracias, como os EUA, se reconhecia a persistência de "authoritarian enclaves" (enclaves autoritários), onde poderes locais ainda mandavam de uma forma altamente antidemocrática, apesar da estrutura democrática do governo nacional (MICKEY, 2013). ${ }^{2}$

Estes debates provocaram novos olhares sobre a democratização, reconhecendo-a como um processo contínuo, em vez de um evento pontual, com retrocessos e avanços. É um processo pouco equilibrado, inconsistente, irregular e variável pelo território nacional. Surgiram novas questões a investigar. Em vez de: "como um país se torna uma democracia?" - pergunta-se: “como progride a democratização?" "Quais são os seus mecanismos?" Um fator principal nos processos de democratização tem a ver com as relações entre Estado, nas suas três esferas, e o cidadão. Nos últimos dez anos, o Brasil tornou-se um foco de estudos, no âmbito destes discursos, com suas novas políticas públicas e instrumentos de participação social.

Os Pontos de Cultura talvez figurem entre os mais inovadores e radicais destas novas políticas. Reconhecendo que "não cabe ao Estado fazer cultura," procurava-se "desesconder" diversas manifestações culturais, principalmente nas "zonas marrons" do país, seja nas áreas rurais do interior ou nos bairros periféricos das grandes cidades. Reconhecendo os agentes sociais como os verdadeiros "fazedores de cultura" e o papel do Estado de apoiar processos culturais já existentes nestas comunidades, e conectando estes agentes culturais em redes horizontais, o programa vislumbrou estabelecer novas

\footnotetext{
2 Eventos atuais, como o assassinato de jovens negros por policias, demonstram a persistência de abusos por poderes locais nos EUA.
} 
relações entre o Estado brasileiro e seus cidadãos. Turino afirma no seu livro Pontos de Cultura: o Brasil de baixo para cima que 'Por baixo de instituições apodrecidas brota uma nova democracia $(2009$, p. 142). A democracia brota também nos espaços onde existe uma falta de institucionalidade, onde o Estado não chega. Como um programa que procura suavemente estender a mão do Estado até estes lugares, o Ponto de Cultura é, no fundo, um projeto de democratização.

\section{Pontos de Cultura no Estado de Alagoas}

“A cultura é o poder do povo" - grafiti perto do Museu Theo Brandão em Maceió

O caso Alagoano destaca-se pelas características de como o programa Cultura Viva foi desenvolvido e estruturado. É um dos raros casos no qual a Secretaria Estadual de Cultura (SEC) funcionava como Pontão, conveniada diretamente ao Ministério de Cultura (MinC), no primeiro edital do programa, antes do processo de descentralização, uma prática que já não se permite mais. Gestores públicos da SEC assumiram a responsabilidade de articulação da rede, promovendo também a capacitação de pontistas, em várias áreas. Assim, a SEC também acompanhou de perto as dificuldades dos primeiros Pontos do Estado de Alagoas, antes de criar sua própria rede estadual.

Quando o programa foi descentralizado, em 2007, o Secretário de Cultura de Alagoas decidiu só criar uma rede de 20 Pontos, além do fato de que houvesse recursos para 40, observando a necessidade de garantir um acompanhamento de perto, para evitar as falhas dos editais anteriores. Em 2014, lançaram um segundo edital para escolher novos 20 Pontos, ampliando a rede. Vários destes novos Pontos já tinham conhecimento do programa, pelo contato com outros agentes culturais, e alguns até já haviam participado das oficinas realizadas pela SEC, como previa o primeiro edital estadual, mas decidiram não concorrer nesse primeiro edital, por causa dos desafios que anteciparam. Também merece anotar que houve continuidade na gestão da SEC do Programa Cultura Viva, em Alagoas, um fator que impacta a relação sociedade-Estado. Por exemplo, a atual coordenadora estadual do programa ficou no cargo por oito anos.

O caso alagoano também é interessante pelo contexto sociopolítico, no qual o programa Cultura Viva se desenvolve, que manifesta alguns desafios da democratização que nos interessam. Ainda existem lugares específicos onde os recursos públicos não 
chegam, e populações distintas, que ficam excluídas dos espaços de tomada de decisões. Nos estudos sobre a política do Nordeste, surgiu a noção do "coronelismo," o dono latifundiário que mantém controle político sobre a população local, pela força, e ainda há áreas controladas pelos poderes locais de uma forma que desrespeita os direitos civis e políticos da população. Também existem bairros da periferia da capital urbana, Maceió, onde atores armados não estaduais dominam de uma forma altamente antidemocrática. Tragicamente, Alagoas é um dos Estados com maiores índices de pobreza e violência.

Culturalmente, Alagoas também representa um caso bastante relevante. A interseção de tradições nordestinas e afrodescendentes, com a presença de comunidades indígenas, fez nascer diversas manifestações culturais no Estado. Na área da música, por exemplo, no transcurso deste estudo, encontramos tocadores de repente, forró, afoxé, guerreiro, reisado e maracatu. Maceió é uma cidade com um movimento cultural urbano da periferia bastante forte. Sem contar com muitas grandes empresas no Estado, a Lei Rouanet, principal fonte de financiamento para atividades culturais no país, que funciona através da redução de impostos para entidades privadas que investem em projetos culturais aprovados pelo Estado, não é muito ativa. Os grupos culturais dependem mais de recursos que vêm diretamente dos governos.

Nas seguintes páginas, são apresentados casos positivos de alterações nas relações sociedade-Estado, no contexto do programa, casos onde, segundo os participantes, houve mudanças positivas, apesar de dificuldades. Dizer que isto acontece dentro do programa, não significa que seja a regra. Houve casos no qual o programa serviu para distanciar o proponente do Estado ou reforçou relações antidemocráticas em sua comunidade. Está fora do alcance deste estudo, apresentar a proporção destes casos. Mas as observações otimistas apresentadas aqui talvez demonstrem o grande potencial do programa.

\section{IV: Aproximação entre pontistas e Estado:}

"Era uma escola para mim, toda este perrengue com prestação de contas. Eu fui estudar lei. Eu fui estudar contabilidade pública... A gente apanhou para aprender". (Pontista)

"As vezes o artista, ele necessariamente não tem obrigação de ser um bom administrador. Ele é o artista... E o sistema forçou que eles aprendessem. Então, estão aprendendo. Estão virando burocratas. Artistas burocratas". (Gestora pública) 
No contexto do programa Cultura Viva, em Alagoas, houve uma aproximação entre cidadãos que nunca antes haviam tido uma relação com representantes do Estado de Alagoas e os gestores públicos da SEC. Também houve uma significante aprendizagem da sociedade civil, de como se relacionar com o Estado brasileiro, acessando e gerenciando dinheiro público. Ironicamente, estas novas relações e conhecimentos surgiram, em parte, da incongruência entre os objetivos inovadores e os meios burocráticos do programa.

Estas tensões se manifestaram de formas particularmente graves, nos Pontos dos primeiros editais, que foram diretamente conveniados ao MinC, em vez de com a SEC. Refletindo sobre as suas experiências como Ponto conveniado diretamente com o Ministério de Cultura, no primeiro edital, uma pontista comentou: "Como sempre foram os cobaias do ministério, tudo que podia dar errado, deu-se com os primeiros Pontos". Como a Secretaria de Cultura (SEC) do Estado foi escolhida como Pontão, neste primeiro edital, os gestores da SEC acompanhavam de perto estas dificuldades, e até enfrentaram umas delas na sua relação com o MinC. Quando lançaram o primeiro edital do Estado, realizaram várias oficinas de capacitação em gestão de projetos e prestação de contas, antes de conveniar os novos Pontos, para tentar evitar estes problemas na rede estadual.

Uma relação bastante próxima e até íntima desenvolveu-se, entre os pontistas e as gestoras da SEC, em parte por causa da necessidade dos pontistas estarem em constante contato para enfrentar os desafios burocráticos do programa. Quando perguntei a uma pontista, que nunca tinha visitado a SEC antes de ser Ponto, quantas vezes ela já havia ido lá, depois de passar no edital, ela me respondeu: "Perdi a conta". Outro pontista contou-me: "Vou lá [na SEC] quase todo dia". Vários pontistas se referiram à gestora da SEC, Catarina, como a "mãe dos Pontos," e sua assessora, como a "madrinha". Um percussionista explicou: "Catarina se doou mesmo. Fica madrugadas em função de ajudar os outros".

Com a ajuda da SEC, e através de oficinas de capacitação, de troca de informações entre a rede de pontos e mera determinação, muitos pontistas superaram os problemas, mesmo graves, e conseguiram avançar no convênio, realizando as atividades programadas. O caso de um Ponto do primeiro edital do MinC, que oferecia oficinas de teatro em uma comunidade periférica de Maceió, é ilustrativo. A coordenadora do Ponto, 
atriz e moradora da comunidade, contou como a primeira parcela chegou no banco, depois de um longo atraso, sem ela ser avisada. O dinheiro ficou no banco doze dias, sem aplicar, e o grupo teatral foi obrigado a devolver o valor, corrigido em muitos reais. Enfrentaram vários outros entraves, no longo do convênio, mas ela eventualmente conseguia resolver estes problemas, aprendendo, no processo, muito sobre lei, contabilidade pública, gestão cultural, entre outras áreas. O grupo acabou de ser selecionado para o novo edital dos vinte Pontos e ampliou a rede estadual, aplicando os novos conhecimentos para gerar novos recursos públicos.

Em alguns casos, o programa Cultura Viva também facilitou uma relação mais próxima entre pontistas e outras entidades estaduais. Um cantador de reisado contou-me sobre a visita de funcionários do MinC a um Ponto de Cultura no interior do Estado. Ele compôs uma canção para receber as visitantes: "Eu vi um avião voando pelo ar. Quando eu olhei era o governo federal". Com mais de oitenta anos de idade, foi através da sua participação em um Ponto de Cultura que ele conheceu, pela primeira vez, pessoalmente, representantes do governo federal. Mas a relação positiva entre gestores da SEC e pontistas não necessariamente se transferia a outras áreas do Estado, e os pontistas regularmente faziam uma distinção entre o governo e as pessoas que ali trabalham. Um músico me contou: "A Catarina [coordenadora da SEC] brigou pela gente. É o governo que incomoda".

No contexto do programa Cultura Viva, e através da convivência com os servidores públicos, os pontistas adquiriram não só capacidades técnicas, mas também novas habilidades para exercer seus direitos como cidadãos. No período deste estudo, o convênio da SEC, como Pontão, estava acabando, e a atual gestão estava saindo da SEC e a rede dos Pontos estava antecipando a entrada de um novo governo. Foi um momento essencial para os Pontos. Houve discussões intensas entre pontistas as gestoras, dando conselhos e encorajamento, sobre como se apresentar aos candidatos, como um coletivo, comunicando suas demandas para a continuidade do programa, e como criar canais de comunicação, como iguais, com a gestão que ia entrar. Também se discutiu a importância de continuar ocupando as salas da SEC, que eles frequentavam e onde se sentiam acolhidos durante a gestão, saindo e reconhecendo que estes espaços públicos eram deles, como afirmou um pontista: "são espaços do Estado e não do governo. 
Políticas Culturais em Revista, 2(7), p. 178-191, 2014 - www.politicasculturaisemrevista.ufba.br

Este empoderamento político é um processo complicado, pelo qual alianças partidárias, brigas pessoais e simplesmente a dificuldade de assumir a responsabilidade da participação social e da verdadeira gestão compartilhada apresentam desafios a serem enfrentados. Mas neste momento se viu que a sementes brotadas durante a implementação do programa Cultura Viva, em Alagoas, tinham a possibilidade de florescer.

\section{Parcerias com governos municipais}

"Em vez do Ponto depender muito dos governos, os governos dependem muito do Ponto... É o governo que está batendo nas portas". (Pontista)

Os Pontos de Cultura trazem recursos para novas atividades de lazer, meios de comunicação, serviços sociais e formas de expressão nas comunidades onde eles atuam. Às vezes, preenchem uma brecha, por exemplo, em bairros periféricos, onde faltam espaços de lazer ou atividades positivas para os jovens. Em outros casos, oferecem mais uma alternativa ao que já existe, pelas ações do governo local. Uma pontista explicou-me como era na sua cidade, antes da criação do Ponto de Cultura: "A cidade é muito pequena. E a população rural, é o hábito de todas as ações serem feitas pela prefeitura. Tudo o que acontecia... era um evento feito pela prefeitura".

Muitas vezes, os Pontos aportam benefícios à população local, muito além de suas atividades culturais diretas. Por exemplo, um Ponto que é uma rádio comunitária que fica num sítio, há uns quinze minutos, numa estrada do povoado mais próximo, grava propagandas do governo federal estadual, que passam na televisão ou nos outros canais de rádio, para repassar à população local. Aos sábados, chegam ao Ponto músicos de forró, guerreira e reisado, para tocar ao vivo no programa comunitário, mas, nos intervalos entre a música popular, o fundador transmite as propagandas estaduais. Ele explicou:

"O governo lança propaganda de várias maneiras, né? Chamando as propagandas, assim, para vacinação, propagandas sobre epidemias, alertas, vacinação de animais. Enfim, todas essas propagandas que saíam, geralmente em benefício da comunidade, eu entendo que isso é um benefício comum para todos. Então, gravamos isso e rola na rádio o dia inteiro. Nós fazemos porque entendemos que o povo necessita dessa informação" 
As atividades dos Pontos foram vistas, por alguns governos municipais, como uma contribuição bem-vinda à comunidade. Em vários casos, o Ponto virou parceiro do governo local, aportando capacidades e recursos que o próprio governo não tinha. $\mathrm{O}$ coordenador de um Ponto, numa cidade de seis mil habitantes, explicou: "[A prefeitura] não tem, por exemplo, condições de cadastrar bolsa família, fazer o censo escolar. Então, tanto nossos jovens quanto os técnicos participam, porque nós temos ferramentas, nós temos instrumentos, nós temos, por exemplo, internet, papel, materiais". O Ponto serve como um multiplicador das capacidades governamentais, nas cidades pequenas do interior e nas comunidades periféricas de Maceió, fazendo que benefícios públicos, além dos recursos do Ministério de Cultura direcionados ao Ponto, "cheguem na ponta".

O Ponto também pode servir como fonte importante de informações sobre a comunidade onde atua, e de interlocutor entre governo e a população, para o fornecimento de serviços sociais. No quintal de um morador de uma comunidade periférica de Maceió, existe um espaço cultural, que abriga grupos de hip hop, teatro comunitário, militantes culturais, entre outros, e que foi recentemente escolhido como Ponto de Cultura, no último edital do Estado. Um dos fundadores do projeto assim se apresentou para mim: "Sou palhaço". Ele também é músico, ator, poeta, e um líder comunitário respeitado. No dia em que fui visitar o Ponto, chegou uma representante da secretaria de assistência social do município, para conversar com ele sobre a possibilidade de organizar uma festa para o Dia das Crianças, em uma rua da comunidade. Como o governo não tinha conhecimento da população, ela queria saber quantas crianças moravam na comunidade, para saber quantos brinquedos trazer para a festa.

É importante ressaltar que, servindo como intermediário, o Ponto não simplesmente implementa os projetos do Estado, nas suas comunidades, ele medeia essa relação. O artista respondeu:

A gente distribui brincadeiras. Não gostamos de trabalhar com brinquedos. Não. A gente bota teatro, o rei de saco, as coisas mais simples. Por que, distribuição de brinquedo, na nossa análise, tem sido algo excludente e gera competição muito grande...

Em vez de simplesmente fornecer as informações procuradas, ele moldava os termos da interação com o Estado, de uma forma que servia mais aos interesses da comunidade, na 
interpretação dele. Na conversa com a representante, ele também enfatizou a necessidade de estabelecer espaços culturais mais permanentes na comunidade, por exemplo, fechando uma rua para as crianças brincaram, não só por um dia, no dia da festa. Obviamente, este papel de intermediário não foi o resultado do grupo cultural ter sido escolhido como Ponto, muito pelo contrário, foi por causa do projeto cultural ter reconhecimento na comunidade que ele foi reconhecido como Ponto. Mas, em vários casos, o programa Cultura Viva serve para fortalecer pessoas e instituições que servem como ponte entre o Estado e cidadão.

A relação entre governo local e Ponto é uma interação delicada, como discutido em mais detalhes, a seguir, e não resulta sempre em uma parceria saudável.

\section{Autonomia frente aos poderes locais}

"A gente tem autonomia. A gente convida [o governo municipal] para a festa. Manda convite. Só que a gente também não abaixa a cabeça". (Pontista)

Não são todos os Pontos de Cultura que são apoiados pelos governos locais. Pontistas ganham uma visibilidade na comunidade, e às vezes suas atividades para o bem comum são vistas como instrumentos para ganhar popularidade que se transforma em votos na hora de eleições. Vários pontistas explicaram que, no início, os prefeitos achavam que eles tinham ambições políticas nos locais onde moravam. Uma pontista comentou: "De repente, a gente despontou, e eles imaginavam que estou fazendo algo porque quero aparecer para me candidatar... Esse interesse em política, a gente não tem. A gente tem autonomia".

As atividades do Ponto também podem ser malvistas por políticos locais, pelo seu papel em aumentar as demandas da população em áreas onde o governo local não fornece benefícios públicos de uma forma adequada, aumentando a pressão popular. Um pontista de uma área rural explicou: "Se eu estou mostrando ao povo que o povo tem direito a tal, que o cara não dava, ele não gosta, entendeu? Se o cara antes não tinha local aqui, não tinha lazer, agora já tem. Se antes ele não podia reclamar. porque não tinha água, não tinha energia, não sei o quê, aí o Ponto ensina isso, e eles buscam".

Houve casos nos quais o político local tentou se apropriar do Ponto de Cultura, no seu município. Em pelo menos um caso, a prefeitura, ao saber que um projeto cultural no 
seu município foi escolhido como Ponto, queria mediar o contrato, recebendo o financiamento e repassando para o grupo cultural. Outro pontista relatou que a prefeitura da sua cidade demandava que os grupos de artistas do seu Ponto prestassem informações sobre suas atividades e se apresentassem nos eventos do governo. Mas ele entendeu perfeitamente suas responsabilidades como Ponto de Cultura conveniado com a Secretaria de Cultura do Estado: "Temos compromisso com a secretaria estadual e o governo federal, e não local".

Sendo Ponto de Cultura, ajudou alguns cidadãos alagoanos a resistirem a pressões políticas, em lugares onde quem não apoia energeticamente e publicamente o político atual, é considerado contra. Como destinatário de recursos públicos que levam a chancela do Estado, os pontistas sentiam a responsabilidade e o direito de tomar uma posição publicamente neutra, na época das campanhas eleitorais, mantendo sua objetividade diante das brigas partidárias. Um pontista relatou que explicou ao prefeito que não podia colocar sua propaganda de campanha no carro, porque o veículo foi usado para atividades do Ponto de Cultura. Outro pontista afirmou: na sede do Ponto, "não boto foto de político, não". Outro pontista acrescentou: "Eu digo que todo mundo pode botar sua foto, não somos contra ninguém”.

A historia de um Ponto de Cultura do interior de Alagoas é ilustrativa de como o programa pode impactar a dinâmica entre o cidadão e o poder local. A prefeitura chegou a proibir esse Ponto de realizar uma festa junina, onde jovens iam apresentar sua quadrilha, supostamente porque ia coincidir com o mesmo dia do evento da administração municipal. O grupo cultural recebeu o ofício avisando que era vedado realizar atividades culturais durante o mês de junho, às três horas da tarde, numa sextafeira, e a apresentação da quadrilha do Ponto estava marcada para o domingo. A coordenadora resolveu procurar um juizado de plantão, no sábado, para conseguir um mandado de segurança para realizar a festa. Quando eu perguntei o que a motivou a fazer isso, ela respondeu: "A convivência. A troca em rede [estadual de Pontos]. Conta um problema a um colega, e o colega diz: 'Porque é que você não faz isso?... A experiência que a gente vive na rede é de não ficar quieto".

Em geral, ser Ponto de Cultura pode contribuir para certa autonomia a respeito de pressões políticos locais. O fato dos recursos virem diretamente do Estado ou da União, 
distribuído por edital público, significa que agentes culturais escolhidos como Pontos de Cultura não estão sujeitos à mesma "política de balcão" ou ao "balcão de atendimento" para conseguir financiamento para suas atividades, como antes. Uma participante do estudo explicou esta dinâmica:

"No momento que você participa num edital, você tem aquele recurso por mérito, e não fica devendo favor a ninguém. No momento que você vem numa secretaria, numa prefeitura, se cobram bem, de uma certa forma, um apoio político. Porque ele apoiou porque quis, podia ter dado ou não. Ele foi bonzinho, entre áspas".

Vários pontistas afirmaram a importância da autonomia financeira que o programa Cultura Viva traz para quem, antigamente, dependia da "generosidade" do poder local, para receber recursos públicos para realizar seu trabalho. Editais e projetos de largo prazo significam nova independência para grupos ou atores culturais que, antigamente, eram dependentes dos prefeitos para financiar seus eventos ou atividades pontuais.

Merece destacar que, hoje em dia, a prática de apoiar processos artísticos através de editais, em Alagoas, não se limita ao programa Cultura Viva. Em entrevistas, os atuais Secretários de Cultura, do Estado e do município de Maceió, enfatizaram seu compromisso de seguir uma política cultural de editais, com os Pontos de Cultura sendo pioneiros desta mudança maior. É significativo que o edital a nível estadual, para escolher Pontos, foi percebido como justo e imparcial, percepção reforçada pelo fato de que muitos dos pontistas que participaram deste estudo não tinham relação nenhuma com o MinC ou a SEC, antes de serem Pontos de Cultura. Um pontista de uma pequena cidade do interior comentou: "O governo estadual, ele de acordo o edital surge, é aberto. Que quem tiver melhor qualificação, passa”. Porém, também vale lembrar que o fato de ser um edital não garante que a distribuição de recursos seja independente de influência política.

Na realidade, continua havendo uma relação complexa com os políticos locais para os agentes culturais, o que demanda jogo de cintura por parte dos líderes comunitários dos Pontos. Mas os recursos e o reconhecimento de ser Ponto, e talvez o mais importante, a relação em rede, em alguns casos, pode ajudar o cidadão a resistir aos abusos dos seus direitos civis e políticos e diminuir sua dependência do poder local.

VII. Conclusão: democracia inacabada 
"A luta mesmo, pela causa, pela melhoria, sempre está independente de ser Ponto... Era uma visão que os próprios associados [do grupo cultural] já tinham, de lutar para melhorar as condições da comunidade onde a gente vive. As ferramentas é que vão mudando....Quando a gente percebe, tá, não adianta só falar, vamos fazer um abaixoassinado, junto com a carta, explicando porquê... Então essas são as coisas que vão mudando, que a gente entende que isso é uma ferramenta que a gente pode usar". (Pontista)

Baseado em exemplos de experiências de pontistas e gestores públicos no Estado de Alagoas, este artigo afirma que o Programa Cultura Viva tem o potencial de promover alterações nas relações Estado-sociedade, de maneira que impulsionem processos de democratização. Para muitos pontistas, o programa facilita novas relações com gestores estaduais, propiciando aprendizagem que os ajudam a exercer seus direitos como cidadãos. Além de diretamente entregar serviços públicos, em suas comunidades, alguns Pontos também cultivam parcerias que contribuem com a capacidade do governo local de fornecer bens públicos. Finalmente, o Programa serve para aumentar a autonomia dos participantes frente aos poderes locais, ajudando-os a realizar atividades culturais independentes da dinâmica política. Os exemplos aqui apresentados não representam a totalidade do Programa, pois não são uma amostra nem de todos os Pontos do Estado de Alagoas, mas revelam o potencial do Programa em casos positivos.

Muitos estudos em ciências políticas procuram demonstrar relações de causaefeito, revelando as condições ou os estímulos que levam a resultados desejados, por exemplo, a melhoria da democracia. Este artigo não pretende sugerir que o programa Cultura Viva causa mudanças nas relações sociedade-estado. O que causa estes avanços, que se entendem aqui como parte do processo de contínua de democratização, são as pessoas. É o compromisso da gestora pública, é a coragem da pontista da pequena cidade do interior, é a criatividade do artista da periferia, são todos estes que causam as mudanças. Os Pontos de Cultura servem como mediação para estes processos, sendo também uma ferramenta para quem já está lutando para a melhoria de suas condições de vida.

\section{Referências}


Políticas Culturais em Revista, 2(7), p. 178-191, 2014 - www.politicasculturaisemrevista.ufba.br

FREIRE, Paulo. Pedagogia da autonomia: saberes necessários à prática educativa. 6. ed. Rio de Janeiro: Paz e Terra, 1997.

MICKEY, R. Paths Out of Dixie: The Democratization of Authoritarian Enclaves in America's Deep South. New Jersey: Princeton University Press, 2013.

O'DONNELL, G. On the State, Democratization and Some Conceptual Problems: A Latin American View with Glances at Some Postcommunist Countries. World Development, 21, n. 8, p. 1355-1369, 1993.

TURINO, C. Ponto de Cultura: o Brasil de baixo para cima. São Paulo: Anita Garibaldi, 2009. 